\title{
Fiber intake modulates the association of alcohol intake with breast cancer
}

Authors: Isabelle Romieu MD-ScD, Pietro Ferrari $\mathrm{PhD}$, Veronique Chajès $\mathrm{PhD}$, Jordi de Batlle $\mathrm{PhD}$, Carine Biessy, Chiara Scoccianti PhD, Laure Dossus PhD, Marie Christine Boutron MD, PhD, Nadia Bastide, $\mathrm{PhD}$, Kim Overvad PhD, Anja Olsen PhD, Anne Tjønneland MD-PhD, Rudolf Kaaks PhD, Heiner Boeing PhD, Antonia Trichopoulou PhD, Pagona Lagiou PhD, Dimitrios Trichopoulos MD-PhD, Domenico Palli MD-MPH, Sabina Sieri PhD, Rosario Tumino PhD, Paolo Vineis MD-PhD, Salvatore Panico MD, H.B(as). Bueno-de-Mesquita PhD, Carla H Gils MD, Petra H. Peeters MD-PhD, Eiliv Lund $\mathrm{PhD}$, Guri Skeie PhD, Elisabete Weiderpass MD-PhD, J.Ramón Quirós MD, María-Dolores Chirlaque PhD, Eva Ardanaz MD-PhD, María-José Sánchez MD-PhD, Eric J. Duell PhD, Pilar Amiano Etxezarreta $\mathrm{PhD}$, Signe Borgquist MD-PhD, Göran Hallmans PhD, Ingegerd Johansson OD-PhD, Lena Maria Nilsson PhD, Kay-Tee Khaw PhD, Nick Wareham PhD, Timothy J Key PhD, Ruth C Travis PhD, Neil Murphy PhD, Petra A. Wark PhD, Elio Riboli MD-PhD.

Author Affiliations: International Agency for Research on Cancer (IARC), Lyon, France (Dr Romieu,

Dr Scoccianti, Dr Chajes, Dr de Batlle, Dr Ferrari, Ms Biessy); Inserm, Centre for research in Epidemiology and Population Health (CESP), U1018, Nutrition, Hormones and Women's Health team, F-94805, Villejuif, France; Univ Paris Sud, UMRS 1018, F-94805, Villejuif, France; IGR, F-94805, Villejuif, France (Dr Boutron, Dr Dossus, Dr . Bastide); Department of Epidemiology, School of Public Health, Aarhus University, Aarhus, Denmark (Dr Overdad); Research Diet, Genes and Environment Danish Cancer Society Research Center Strandboulevarden, Copenhagen, Denmark (Dr Olsen, Dr Tjønneland); Division of Cancer Epidemiology, German Cancer Research Center (DKFZ), Heidelberg, Germany (Dr Kaaks); Deutsches Institut für Ernährungsforschung Potsdam-Rehbrücke German, Institute of Human Nutrition Potsdam-Rehbrücke (Dr Boeing); Hellenic Health Foundation, 13 Kaisareias Street, Athens, GR-115 27, Greece; WHO Collaborating Center for Food and Nutrition Policies, Department of Hygiene, Epidemiology and Medical Statistics, University of Athens Medical School, Athens, Greece (Dr

This article has been accepted for publication and undergone full peer review but has not been through the copyediting, typesetting, pagination and proofreading process which may lead to differences between this version and the Version of Record. Please cite this article as an 'Accepted Article', doi: 10.1002/ijc.30415

This article is protected by copyright. All rights reserved. 
Trichopoulou); WHO Collaborating Center for Food and Nutrition Policies, Department of Hygiene, Epidemiology and Medical Statistics, University of Athens Medical School, Athens, Greece; Department of Epidemiology, Harvard School of Public Health, Boston, USA; Bureau of Epidemiologic Research, Academy of Athens, Athens, Greece (Dr Lagiou); Department of Epidemiology, Harvard School of Public Health, Boston, USA; Bureau of Epidemiologic Research, Academy of Athens, Athens, Greece; Hellenic Health Foundation, Athens, Greece (Dr Trichopoulos); Molecular and Nutritional Epidemiology Unit, Cancer Research and Prevention Institute - ISPO, Florence- Italy (Dr Palli); Epidemiology and Prevention Unit, Department of Preventive \& Predictive Medicine, Fondazione IRCCS Istituto Nazionale dei Tumori, Milan - Italy (Dr Sieri); Cancer Registry and Histopathology Unit, "Civic - M.P.Arezzo" Hospital, ASP Ragusa, Italy (Dr Tumino); School of Public Health, Imperial College London, London, HuGeF Foundation Torino Italy (Dr Vineis); Dipartimento di Medicina Clinica e Chirurgia Federico II University, Naples, Italy (Dr Panico); National Institute for Public Health and the Environment (RIVM), Bilthoven, The Netherlands, Department of Gastroenterology and Hepatology University Medical Centre, Utrecht, The Netherlands, The School of Public Health, Imperial College London, London, United Kingdom; Department of Social \& Preventive Medicine, Faculty of Medicine University of Malaya, Kuala Lumpur, Malaysia (Dr Bueno-de-Mesquita); Department of Epidemiology, Julius Center for Health Sciences and Primary Care, University Medical Center Utrecht (Dr Gils and Dr. Peeters); Department of Epidemiology and Biostatistics, School of Public Health, Faculty of Medicine, Imperial College, London, UK (Dr Peeters); Department of community medicine, University of Troms $\varnothing$ - the Arctic University of Norway, Tromsø, Norway (Dr Eiliv, Dr Skeie); Department of Community Medicine, Faculty of Health Sciences, University of Tromsø, The Arctic University of Norway, Tromsø, Norway, Department of Research, Cancer Registry of Norway, Oslo, Department of Medical Epidemiology and Biostatistics, Karolinska Institutet, Stockholm, Sweden, Samfundet Folkhälsan, Helsinki, Finland (Dr Weiderpass); Public Health Directorate, Asturias, Spain (Dr Quiros); Department of Epidemiology, Murcia Regional Health Authority, Murcia, Spain, CIBER Epidemiology and Public Health CIBERESP, Spain (Dr Chirlaque); Navarre Public Health Institute, Pamplona, Spain, CIBER Epidemiology and Public Health 
CIBERESP, Spain (Dr Ardanaz); Escuela Andaluza de Salud Pública, Granada, Spain, CIBERESP, Spain, Instituto de Investigación Biosanitaria de Granada, Granada, Spain (Dr Sanchez); Unit of Nutrition, Environment and Cancer, Catalan Institute of Oncology (ICO-IDIBELL), Barcelona, Spain (Dr Duell); Public Health Division of Gipuzkoa, BioDonostia Research Institute, San Sebastian; CIBER Epidemiology and Public Health CIBERESP, Spain (Dr Amiano); Division of Oncology, Department of Clinical Sciences, Lund University Lund, Sweden (Dr Borgquist); Department of Public Health and Clinical Medicine, Nutritional Research, Umeå University, Umeå, Sweden (Dr Hallmans); Department of Odontology, Umeå University, Umeå, Sweden (Dr Johansson); Public Health and Clinical Medicine/Nutritional research, Umeå university, Umeå, Sweden (Dr Nillson); University of Cambridge School of Clinical Medicine, Cambridge, United Kingdom (Dr Khaw); MRC Epidemiology Unit and University of Cambridge School of Clinical Medicine, Cambridge United Kingdom (Dr Wareham); Cancer Epidemiology Unit, Nuffield Department of Clinical Medicine, University of Oxford, Oxford, United Kingdom (Dr Key, Dr Travis); Department of Epidemiology and Biostatistics, School of Public Health, Imperial College London, London, United Kingdom (Dr Murphy, Dr Wark, Dr Riboli);

Short title: Fiber and alcohol intake and breast cancer

Corresponding author: Dr Isabelle Romieu, International Agency for Research on Cancer, 150 cours Albert Thomas, 69373 Lyon cedex, France. Phone: +33472738094; Fax: +33472738361; Email: romieui@iarc.fr

\section{Novelty and impact}

Alcohol intake increases the risk of breast cancer, while fiber intake has a protective effect. In this prospective study analysis of women enrolled in the European Prospective Investigation into Cancer and Nutrition, a significant interaction was observed between alcohol and fiber intakes, women with high alcohol intake and low fiber intake had the highest risk for breast cancer. This result supports a modulating effect of fiber intake on the adverse effect of alcohol intake. 


\begin{abstract}
Alcohol intake has been related to an increased risk of breast cancer (BC) while dietary fiber intake has been inversely associated to $\mathrm{BC}$ risk. A beneficial effect of fibers on ethanol carcinogenesis through their impact on estrogen levels is still controversial. We investigated the role of dietary fiber as a modifying factor of the association of alcohol and breast cancer using data from the European Prospective Investigation into Cancer and Nutrition (EPIC). This study included 334,850 women aged 35-70 years at baseline enrolled in the ten countries of the EPIC study and followed up for 11.0 years on average. Information on fiber and alcohol intake at baseline and average lifetime alcohol intake were calculated from country-specific dietary and lifestyle questionnaires. Hazard ratios (HR) of developing invasive breast cancer according to different levels of alcohol and fiber intake were computed. During 3,670,439 person-years, 11,576 incident breast cancer cases were diagnosed. For subjects with low intake of fiber $(<18.5$ $\mathrm{g} /$ day), the risk of BC per 10g/day of alcohol intake was 1.06 (1.03-1.08) while among subjects with high intake of fiber $(>24.2 \mathrm{~g} /$ day) the risk of BC was $1.02(0.99-1.05)$ (test for interaction $p=0.011$ ). This modulating effect was stronger for fiber from vegetables. Our results suggest that fiber intake may modulate the positive association of alcohol intake and BC.
\end{abstract}

John Wiley \& Sons, Inc.

This article is protected by copyright. All rights reserved. 


\section{()}

\section{Introduction}

A consistent association has been observed between alcohol intake and breast cancer (BC) among pre- and postmenopausal women ${ }^{1}$.We recently reported in the EPIC cohort that for each $10 \mathrm{~g} / \mathrm{day}$ increase in alcohol intake the HR increased by $4.2 \%(95 \% \mathrm{CI}, 2.7 \%-5.8 \%)^{2}$. Taking 0 to $5 \mathrm{~g} / \mathrm{day}$ as a reference, alcohol intake of $>5$ to $15 \mathrm{~g}$ /day was related to a $5.9 \%$ increase of breast cancer risk (95\% CI, 1\%-11\%). A significant increasing trend was observed between alcohol intake for different types of tumor receptors status (ER+/PR+, ER-/PR-, HER2- and ER-/PR-/HER2-) tumors. While it is widely accepted that dietary fiber intake inversely correlates to $\mathrm{BC}$ risk, ${ }^{3} \mathrm{a}$ beneficial effect on ethanol carcinogenesis through their impact on estrogen levels, ${ }^{4}$ is still controversial $^{5}$. It is therefore important to evaluate the association of alcohol intake and $\mathrm{BC}$ phenotypes and the potential modulating role of fiber intake.

\section{Material and Methods}

EPIC is a large prospective cohort study conducted in 23 centers in Denmark, France, Germany, Greece, Italy, Norway, Spain, Sweden, the Netherlands, and the United Kingdom. EPIC recruited a total of 367,993 women, aged 35-70 years who gave informed consent and completed questionnaires on diet, lifestyle, and medical history ${ }^{6}$. Women with prevalent cancers other than non-melanoma skin cancer at recruitment $(n=19,853)$, missing diagnosis or censoring date $(n=$ $2,892)$, missing dietary or lifestyle information $(n=3,339)$, in the top and bottom $1 \%$ of the ratio of energy intake to estimated energy requirement, calculated from age, sex, body weight and height $(n=6,753)$ were excluded from the analysis. Only first primary BC cases were retained in the analysis (217 non-primary BCs excluded). The EPIC study was approved by the IARC Ethics Committee and by the local ethics committees of the participating centers.

\section{Dietary assessment and alcohol intake}

For the present study, intake of alcoholic beverages at baseline was calculated from dietary questionnaires which have been previously validated for alcohol intake ${ }^{6,7}$. Subjects reported the number of standard glasses of beer, cider, wine, sweet liquor, distilled spirits or fortified wines consumed per day/week during the 12 months prior to recruitment. In each country, intake was 
calculated based on the estimated average glass volume and ethanol content for each type of alcoholic beverage, using information collected in highly standardized 24-hr dietary recalls from a subset of the cohort ${ }^{8,9}$. Among $76 \%$ of the participants with available information, average lifetime alcohol intake was determined ${ }^{2}$. Estimation of dietary fiber intake has been described previously ${ }^{10}$. In brief, dietary fiber was defined by the AOAC (Association of Official Agricultural Chemists) gravimetric method for Total Dietary Fiber, ${ }^{11}$ and includes soluble and insoluble forms (including lignin) of non-starch polysaccharides and resistant starch ${ }^{10,11}$. The dietary fiber variable used in this work was obtained using the EPIC Nutrient Data Base (ENDB) in which the dietary fiber composition of foods was harmonized across the participating European countries to take into account the different analytical methods used ${ }^{12}$.

\section{Anthropometric measurements}

Weight and height were measured at baseline, while the subjects were not wearing shoes, to the nearest $0.1 \mathrm{~kg}$, or to the nearest $0.1,0.5$, or $1.0 \mathrm{~cm}$, depending on the center ${ }^{13}$. In France, Norway, and Oxford, height and weight were self-reported on a questionnaire. The procedures used to account for procedural differences between centers in the collection of anthropometric measurements, are described elsewhere ${ }^{14,15}$.

\section{Outcome assessment}

Incident BC cases were identified through population cancer registries (Denmark, Italy (all centers but Naples), the Netherlands, Norway, Spain, Sweden and United Kingdom) or by a combination of methods including health insurance records, cancer and pathology registries and active follow-up (France, Germany, Naples and Greece). Subjects were followed up from study entry and until cancer diagnosis (except for non-melanoma skin cancer cases), death, emigration or until the end of the follow-up period (varying from 2004 and 2010 depending on the center), whichever occurred first. Information on ER, Progesterone Receptor (PR) and Human Epidermal Growth Factor Receptor 2 (HER2) was provided by each center using the same techniques to collect incident BC cases.

Menopausal status was determined as previously reported in the EPIC study. ${ }^{16,17}$.

\section{Statistical analysis}


Cox proportional hazards regression models were used to quantify the association between alcohol intake and the risk of BC. Age was the primary time variable, and the Breslow method was adopted for handling ties ${ }^{18}$. Analyses were conducted for all women as well as by receptors status. Systematic adjustments were made for menopausal status, weight, height, smoking status (never, former, smoker and unknown), education, physical activity and energy intake from nonalcohol sources. In addition, the following variables were included in the models: age at menarche, age at birth of first child, age at menopause, whether the contraceptive pill was ever used, and whether menopausal hormone therapy was ever used. Analyses were stratified by study center to control for differences in questionnaires, follow-up procedures and other centerspecific effects. To further control for the possible confounding effect of age, models were stratified by age at recruitment in 1-year categories ${ }^{19}$.

Alcohol intake (baseline as well as averaged intake over lifetime) was modelled using continuous and categorical $(<5,5-15,>15 \mathrm{~g}$ /day) variables and the association was expressed for an increase in $10 \mathrm{~g}$ of alcohol intake per day ${ }^{2}$. Dietary fiber intake was modelled as continuous and categorical (low, medium and high intake according to distribution in the controls) for total fiber intake as well as for fiber sources (vegetables, fruits and cereals). Multivariate hazard ratios for breast cancer according to the combined effects of dietary fibers (g/day) and alcohol (drink/week) were explored. The statistical significance of interactions was assessed using likelihood ratio tests based on the models with and without the interaction terms formed by the product of dietary fiber intake (continuous) and the value of alcohol intake at recruitment as well as averaged lifetime intake (continuous). Similar analyses were carried out according to estrogen receptor status. For all models, the proportional hazards assumption was satisfied, and was evaluated via inclusion into the disease model of interaction terms between exposure and attained age (data not shown). Statistical tests were two sided, and p-values $<0.05$ were considered significant. All analyses were performed using SAS version 9.2 (SAS Institute, 1999).

\section{Results}

During an average of 11.0 years of follow up $(3,670,439$ person-years) of 334,850 study participants, the EPIC study documented 11,576 invasive incident BC cases. The mean age at 
recruitment was 50.8 years, and the mean age at $\mathrm{BC}$ diagnosis was 59.4 years. Among them the distribution was as follows: 35.2\% were premenopausal, $43.1 \%$ postmenopausal (18.8\% of women were unknown and 2.9\% reported bilateral ovariectomy). ER, PR and HER2 status was available only in $63 \%, 52 \%$ and $20 \%$ of cancer cases, respectively, and were distributed as follows, $80 \% \mathrm{ER}^{+}$tumors and 20\% $\mathrm{ER}^{-}, 64 \% \mathrm{PR}^{+}$tumors and 36\% $\mathrm{PR}^{-}, 25 \% \mathrm{HER}^{+}$and $75 \%$ HER2-.

Table 1 presents the amount of fiber intake and mean intake of alcohol according to tertiles of fiber intake for total fiber, fiber from vegetables, fruits and cereals. The mean alcohol intake in the first tertile (lowest) of total fiber intake was 8.06 grams/day, $7.32 \mathrm{gr} /$ day in the second tertile and $6.76 \mathrm{gr} / \mathrm{day}$ in the third (highest) tertile of fiber intake. Regarding specific types of fiber intake, the mean alcohol intake was $8.68 \mathrm{gr} /$ day in the first tertile of fibers from fruit intake, $7.30 \mathrm{gr} / \mathrm{day}$ in the second tertile and $6.70 \mathrm{gr} /$ day in the third tertile. Alcohol intake was slightly lower among women with the highest total fiber intake $(\mathrm{p}<.0001)$.and with the highest fibers from fruit intake $p=<.0001$ ). No significant difference in alcohol intake was observed among tertiles of fiber from vegetables or cereals. (alcohol intake in gr/day within tertiles of fiber intake: 7.26,7.55 and 7.28 gr/day for fiber from vegetables and 7.52,7.68,7.39gr/day for fiber from cereals).

Alcohol consumption was significantly related to breast cancer among women with low total fiber intake ( $<18.5 \mathrm{~g} /$ day) with an increased risk of 5.7\% $(95 \%$ CI $3.2 \%$ to $7.9 \%)$ per $10 \mathrm{~g} /$ alcohol per day (equivalent to 1 drink per day). However, among women with high fiber intake $(>24.2 \mathrm{~g} /$ day) the risk was not significant $(1.2 \% 95 \%$ CI $-0.6 \%$ to $4.9 \%)$. We observed a significant interaction between alcohol and fiber intake on breast cancer risk $(p=0.011)$. When data where stratified by estrogen receptor status, we observed similar results in $\mathrm{ER}^{+}$and $\mathrm{ER}^{-}$ tumors with a significant increased risk of BC with alcohol consumption among women with low fiber intake. The test for interaction between alcohol and fiber intake was marginally significant for $\mathrm{ER}^{+}$tumors $(\mathrm{p}=0.10)$ and the small number of $\mathrm{ER}^{-}$, tumors precluded definite conclusion.

We explored the effect of different sources of fiber and observed that fiber from vegetable sources had the strongest protective effect on overall BC. Among women with low vegetable fiber intake $(<3.2 \mathrm{~g} /$ day) the increased risk of $\mathrm{BC}$ per $10 \mathrm{~g} /$ day of alcohol consumption was $6.3 \%$ 
(3.7 to $9.0 \%$ ) while among women with a high intake of fiber $(>5.5 \mathrm{~g} / \mathrm{day})$ the risk was nonsignificant $(2.3 \% 95 \% \mathrm{CI}-0.2 \%$ to $4.8 \%)$. A significant interaction between alcohol and fiber intake was observed $(\mathrm{p}=0.0033)$. For fiber from other sources, no significant protective effect was observed although $\mathrm{BC}$ risk was consistently lower among women with high fiber intake from fruits and cereals (Table 2).

Figure 1 presents the HRs associated to categories of alcohol intake and fiber intake (tertiles). Compared to women with low alcohol ( $<5 \mathrm{~g} /$ day or $2 \mathrm{dr} /$ week) and high fiber $(>24 \mathrm{~g} /$ day $)$ intakes (as reference category), women with a high alcohol ( $>15 \mathrm{~g} /$ day or $>10 \mathrm{dr} /$ week) and low fiber $(<18.5 \mathrm{~g} /$ day $)$ intakes had a 35\% (95\% CI, 23\%-48\%) increased BC risk. Among women with high alcohol intake and high fiber, the increased risk was 12\% (95\% CI, 2\% $-23 \%$; test of heterogeneity $\mathrm{p}=0.005$ ) while among women with low alcohol intake and low fiber the increased risk was $8 \%(95 \% \mathrm{CI}, 0 \%-18 \%)$. When both alcohol and fiber intakes were considered as continuous variables we observed a significant interaction $(p=0.01)$.

Additional analyses using averaged lifetime intake instead of baseline alcohol consumption ( $\mathrm{n}=$ $9,025)$ or restricting cases to those occurring at least 2 years after baseline recruitment $(\mathrm{n}=$ 9,916), provided similar results as presented above.

\section{Discussion}

In this prospective study of 334,850 women and 11,576 incident invasive BC cases, fiber intake appeared to modulate the adverse effect of ethanol on BC risk. This effect was most apparent for fiber from vegetables sources.

Our findings are in accordance with a recent result from the SUVIMAX cohort suggesting a modulating effect of fiber intake on the adverse effect of alcohol intake on breast cancer although no significant interaction was observed. However, this study included only a small number of breast cancer cases $(n=158)^{20}$.

Alcohol has been shown to increase sex hormone levels ${ }^{21}$ and a reduction of circulating estrogen and androstenedione has been observed in epidemiological and intervention studies in relation to fiber intake ${ }^{3}$. Fiber may bind estrogen in the colon thus increasing the fecal excretion of estrogens. In addition, dietary fiber may reduce the hydrolysis of conjugated estrogen resulting in 
less reabsorption ${ }^{3}$. The modulating effect that we observed for fibers supports both the notion that fiber-rich foods may counteract the enhanced estrogen responsiveness due to alcohol drinking and that different dietary habits may confound the association of alcohol drinking with $\mathrm{BC}^{4}$. However, plausible anti-cancer mechanisms and explanations exist for dietary fibers from different food sources (including an array of phytochemicals such antioxidants and phytoestrogens, the glycemic/insulinemic control, the substitutive effect of foods associated with high $\mathrm{BC}$ risks). It is largely unclear what specific biological mechanisms may underlie observed differences in the associations of fruit, vegetable and cereal fibers with BC in the present analysis. In addition, the biological mechanism underlying the differential associations of risk factors with hormone-receptor positive and negative BC remains to be fully characterized ${ }^{22-24}$. So far, epidemiological evidence suggests that factors linked to estrogen metabolism are more strongly related to $\mathrm{ER}^{+}$tumors, while $\mathrm{ER}^{-}$might be more susceptible to non-hormonal factors, including diet ${ }^{22-24}$.

In our population $30 \%$ of women had fiber intake in accordance with the current recommendation of $25 \mathrm{~g} /$ day $^{25}$. With regards to cancer risk, the lowest level of alcohol intake has been recommended ${ }^{26}$. The mean alcohol intake in our population was $9 \mathrm{~g} / \mathrm{day}, 48.5 \%$ consumed less than $5 \mathrm{~g} /$ day, $32 \%$ between 5 and $15 \mathrm{gr} /$ day and $19.5 \%$ more than $15 \mathrm{~g} /$ day (excluding the non consumers).

Major strengths of our study include the prospective and population-based design, a large sample size, detailed information on alcohol intake at different periods of life, data on HR status of the breast tumors, excellent follow-up and larger numbers of cases which provided good power for subgroups analyses. Information on alcohol intake was self-reported and potential misclassification may have underestimated the effect of alcohol intake. Still, assessment of alcohol intake has been shown to be reliable in the EPIC cohort ${ }^{7,27}$ and the prospective setting of our study minimizes recall bias on baseline and average lifetime alcohol intake. Residual confounding by misreporting of alcohol intake cannot be ruled out. Women with poor diet with a low fiber intake may report differentially (underreport) alcohol intake leading to a higher RR per $10 \mathrm{~g} /$ day of alcohol among women with low fiber intake, therefore overestimating a potential protective effect of fiber. However, the fact that the modulating effect of fiber intake is observed mostly for vegetables sources support a true association. In addition, the multi-centric nature of 
the EPIC study made it possible to evaluate this association based on a large variation of dietary exposure, with total fiber ranging between 16 to $27 \mathrm{~g}$ /day, depending on the center. Further adjustment of our model for folate intake as marker of healthy diet and life style did not affect our results supporting the protective effect of fiber. Among the main limitations of the study, it should be noted that diet was assessed at recruitment only, no information was available on soluble or insoluble sub-types of dietary fiber, and on cancer histology.

The results of this study suggest that dietary fiber intake, especially from vegetable sources may modulate the adverse effect of alcohol consumption on the risk of breast cancer. The beneficial effect observed in our study deserves further investigation in future studies to better assess the mechanisms and specific protective effect of sources of fibers on tumor subtypes.

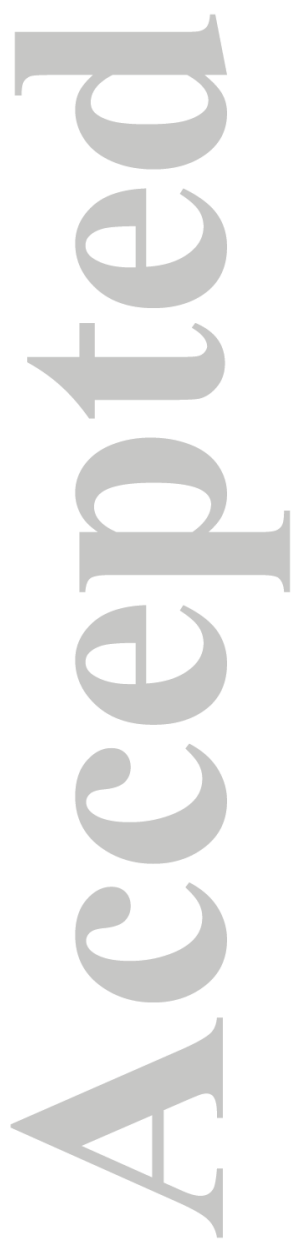




\section{References}

1. Scoccianti C, Lauby-Secretan B, Bello PY, Chajes V, Romieu I. Female breast cancer and alcohol consumption: a review of the literature. Am. J. Prev. Med 2014;46:S16-S25.

2. Romieu I, Scoccianti C, Chajes V, de Batlle J, Biessy C, Dossus L, Baglietto L, Clavel-Chapelon F, Overvad K, Olsen A, Tjonneland A, Kaaks R, et al. Alcohol intake and breast cancer in the European prospective investigation into cancer and nutrition. International journal of cancer Journal international du cancer 2015;137:1921-30.

3. Aune D, Chan DS, Greenwood DC, Vieira AR, Rosenblatt DA, Vieira R, Norat T. Dietary fiber and breast cancer risk: a systematic review and meta-analysis of prospective studies. Ann. Oncol 2012;23:1394-402.

4. Maskarinec G, Morimoto Y, Takata Y, Murphy SP, Stanczyk FZ. Alcohol and dietary fibre intakes affect circulating sex hormones among premenopausal women. Public Health Nutr 2006;9:87581.

5. Ferrari $P$, Rinaldi S, Jenab M, Lukanova A, Olsen A, Tjonneland A, Overvad K, Clavel-Chapelon F, Fagherazzi G, Touillaud M, Kaaks R, von RA, et al. Dietary fiber intake and risk of hormonal receptordefined breast cancer in the European Prospective Investigation into Cancer and Nutrition study. Am. J. Clin. Nutr 2013;97:344-53.

6. Riboli E, Hunt KJ, Slimani N, Ferrari P, Norat T, Fahey M, Charrondiere UR, Hemon B, Casagrande C, Vignat J, Overvad K, Tjonneland A, et al. European Prospective Investigation into Cancer and Nutrition (EPIC): study populations and data collection. Public Health Nutr 2002;5:1113-24.

7. Kaaks R, Slimani N, Riboli E. Pilot phase studies on the accuracy of dietary intake measurements in the EPIC project: overall evaluation of results. European Prospective Investigation into Cancer and Nutrition. Int J Epidemiol 1997;26 Suppl 1:S26-S36.

8. Sieri S, Krogh V, Saieva C, Grobbee DE, Bergmann M, Rohrmann S, Tjonneland A, Ferrari P, Chloptsios Y, Dilis V, Jenab M, Linseisen J, et al. Alcohol consumption patterns, diet and body weight in 10 European countries. Eur. J. Clin. Nutr 2009;63 Suppl 4:S81-100.

9. Slimani N, Ferrari P, Ocke M, Welch A, Boeing H, Liere M, Pala V, Amiano P, Lagiou A, Mattisson I, Stripp C, Engeset D, et al. Standardization of the 24-hour diet recall calibration method used in the european prospective investigation into cancer and nutrition (EPIC): general concepts and preliminary results. Eur J Clin Nutr 2000;54:900-17.

10. Cust AE, Skilton MR, van Bakel MM, Halkjaer J, Olsen A, Agnoli C, Psaltopoulou T, Buurma E, Sonestedt E, Chirlaque MD, Rinaldi S, Tjonneland A, et al. Total dietary carbohydrate, sugar, starch and fibre intakes in the European Prospective Investigation into Cancer and Nutrition. Eur. J. Clin. Nutr 2009;63 Suppl 4:S37-S60.

11. Vries JWD, Rader JI. Historical perspective as guide for identifying and developing applicable methods for dietary fiber. J AOAC Int 2005;88:1349.

12. Slimani N, Deharveng G, Unwin I, Southgate DA, Vignat J, Skeie G, Salvini S, Parpinel M, Moller A, Ireland J, Becker W, Farran A, et al. The EPIC nutrient database project (ENDB): a first attempt to standardize nutrient databases across the 10 European countries participating in the EPIC study. Eur. J Clin. Nutr 2007;61:1037-56.

13. Friedenreich C, Cust A, Lahmann PH, Steindorf K, Boutron-Ruault MC, Clavel-Chapelon F, Mesrine S, Linseisen J, Rohrmann S, Boeing H, Pischon T, Tjonneland A, et al. Anthropometric factors and risk of endometrial cancer: the European prospective investigation into cancer and nutrition. Cancer Causes Control 2007;18:399-413.

14. Haftenberger M, Lahmann PH, Panico S, Gonzalez CA, Seidell JC, Boeing H, Giurdanella MC, Krogh V, Bueno-de-Mesquita HB, Peeters PH, Skeie G, Hjartaker A, et al. Overweight, obesity and fat distribution in 50- to 64-year-old participants in the European Prospective Investigation into Cancer and Nutrition (EPIC). Public Health Nutr 2002;5:1147-62. 
15. Slimani N, Deharveng G, Charrondiere RU, van Kappel AL, Ocke MC, Welch A, Lagiou A, van Liere M, Agudo A, Pala V, Brandstetter B, Andren C, et al. Structure of the standardized computerized 24-h diet recall interview used as reference method in the 22 centers participating in the EPIC project. European Prospective Investigation into Cancer and Nutrition. Comput. Methods Programs Biomed 1999;58:251-66.

16. Kaaks R, Berrino F, Key T, Rinaldi S, Dossus L, Biessy C, Secreto G, Amiano P, Bingham S, Boeing $\mathrm{H}$, Bueno de Mesquita HB, Chang-Claude J, et al. Serum sex steroids in premenopausal women and breast cancer risk within the European Prospective Investigation into Cancer and Nutrition (EPIC). Journal of the National Cancer Institute 2005;97:755-65.

17. Kaaks R, Rinaldi S, Key TJ, Berrino F, Peeters PH, Biessy C, Dossus L, Lukanova A, Bingham S, Khaw KT, Allen NE, Bueno-de-Mesquita HB, et al. Postmenopausal serum androgens, oestrogens and breast cancer risk: the European prospective investigation into cancer and nutrition. Endocr. Relat Cancer 2005;12:1071-82.

18. Thiebaut AC, Benichou J. Choice of time-scale in Cox's model analysis of epidemiologic cohort data: a simulation study. Stat. Med 2004;23:3803-20.

19. Ferrari P, Day NE, Boshuizen HC, Roddam A, Hoffmann K, Thiebaut A, Pera G, Overvad K, Lund E, Trichopoulou A, Tumino R, Gullberg B, et al. The evaluation of the diet/disease relation in the EPIC study: considerations for the calibration and the disease models. Int J Epidemiol 2008;37:368-78. 20. Chhim AS, Fassier P, Latino-Martel P, Druesne-Pecollo N, Zelek L, Duverger L, Hercberg S, Galan P, Deschasaux M, Touvier M. Prospective association between alcohol intake and hormonedependent cancer risk: modulation by dietary fiber intake. Am J Clin Nutr 2015;102:182-9.

21. Hirko KA, Spiegelman D, Willett WC, Hankinson SE, Eliassen AH. Alcohol consumption in relation to plasma sex hormones, prolactin, and sex hormone-binding globulin in premenopausal women. Cancer Epidemiol Biomarkers Prev 2014;23:2943-53.

22. Althuis MD, Fergenbaum JH, Garcia-Closas M, Brinton LA, Madigan MP, Sherman ME. Etiology of hormone receptor-defined breast cancer: a systematic review of the literature. Cancer Epidemiol. Biomarkers Prev 2004;13:1558-68.

23. Colditz GA, Rosner BA, Chen WY, Holmes MD, Hankinson SE. Risk factors for breast cancer according to estrogen and progesterone receptor status. J Natl. Cancer Inst 2004;96:218-28.

24. Yang XR, Chang-Claude J, Goode EL, Couch FJ, Nevanlinna H, Milne RL, Gaudet M, Schmidt MK, Broeks A, Cox A, Fasching PA, Hein R, et al. Associations of breast cancer risk factors with tumor subtypes: a pooled analysis from the Breast Cancer Association Consortium studies. J Natl. Cancer Inst 2011;103:250-63.

25. United State Department of Agriculture, United States Department of Health and Human Services. Dietary Guidelines for Americans 2010, 2010.

26. IARC. European Code against Cancer.

27. Tjonneland A, Overvad K, Haraldsdottir J, Bang S, Ewertz M, Jensen OM. Validation of a semiquantitative food frequency questionnaire developed in Denmark. Int J Epidemiol 1991;20:906-12. 
Table 1. Levels of fiber and alcohol intakes by tertiles of total fiber and fiber from different sources

\begin{tabular}{|c|c|c|c|c|c|c|c|c|}
\hline & \multicolumn{2}{|c|}{ Tertiles of total fibers } & \multicolumn{2}{|c|}{ Tertiles of fibers from vegetables } & \multicolumn{2}{|c|}{ Tertiles of fibers from fruits } & \multicolumn{2}{|c|}{ Tertiles of fibers from cereals } \\
\hline & Total fibers ${ }^{(1)}$ & Alcohol $^{(2)}$ & $\begin{array}{c}\text { Fibers from } \\
\text { vegetables }\end{array}$ & Alcohol $^{(2)}$ & $\begin{array}{c}\text { Fibers from } \\
\text { fruits }\end{array}$ & Alcohol $^{(2)}$ & $\begin{array}{c}\text { Fibers from } \\
\text { cereals }^{(1)}\end{array}$ & Alcohol $^{(2)}$ \\
\hline Low & $\begin{array}{c}14.94 \\
(11.18-17.92)\end{array}$ & $\begin{array}{c}8.06 \\
(0.13-21.61)\end{array}$ & $\begin{array}{c}2.24 \\
(1.28-3.05)\end{array}$ & $\begin{array}{c}7.26 \\
(0.11-19.62)\end{array}$ & $\begin{array}{c}1.78 \\
(0.58-2.76)\end{array}$ & $\begin{array}{c}8.68 \\
(0.13-23.57)\end{array}$ & $\begin{array}{c}3.80 \\
(2.11-5.24)\end{array}$ & $\begin{array}{c}7.52 \\
(0.12-20.38)\end{array}$ \\
\hline Medium & $\begin{array}{c}21.23 \\
(19.04-23.50)\end{array}$ & $\begin{array}{c}7.32 \\
(0.13-19.52)\end{array}$ & $\begin{array}{c}4.26 \\
(3.44-5.15)\end{array}$ & $\begin{array}{c}7.55 \\
(0.15-19.94)\end{array}$ & $\begin{array}{c}4.15 \\
(3.22-5.09)\end{array}$ & $\begin{array}{c}7.30 \\
(0.14-19.19)\end{array}$ & $\begin{array}{c}7.14 \\
(5.90-8.51)\end{array}$ & $\begin{array}{c}7.68 \\
(0.13-20.31)\end{array}$ \\
\hline High & $\begin{array}{c}29.72 \\
(24.84-36.35)\end{array}$ & $\begin{array}{c}6.76 \\
(0.13-18.29)\end{array}$ & $\begin{array}{c}7.74 \\
(5.72-10.56)\end{array}$ & $\begin{array}{c}7.28 \\
(0.13-19.62)\end{array}$ & $\begin{array}{c}8.38 \\
(5.75-12.06)\end{array}$ & $\begin{array}{c}6.70 \\
(0.12-18.12)\end{array}$ & $\begin{array}{c}12.17 \\
(9.38-15.95)\end{array}$ & $\begin{array}{c}7.39 \\
(0.14-19.82)\end{array}$ \\
\hline
\end{tabular}

${ }^{1}$ country-adjusted means and 10th-90th percentile values of fiber intake

2 country-adjusted means and 10th-90th percentile values of baseline alcohol intake

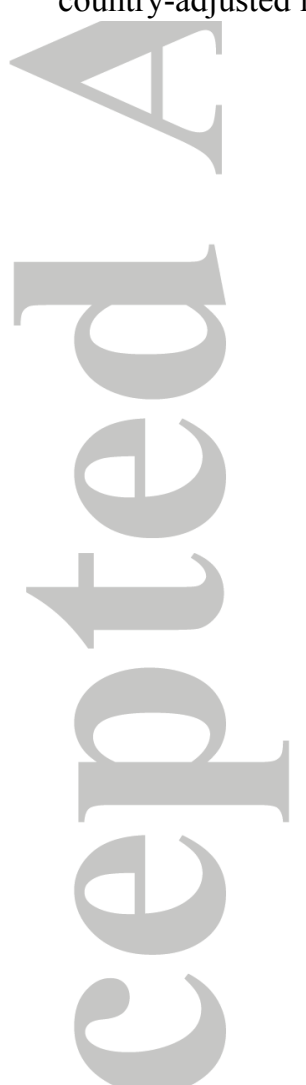


Table 2. HR estimates of $\mathbf{1 0} \mathrm{g} /$ day increase of alcohol intake associated to $\mathrm{BC}$ risk by tertiles oftotal dietary fiber intake and fiber from different sources.

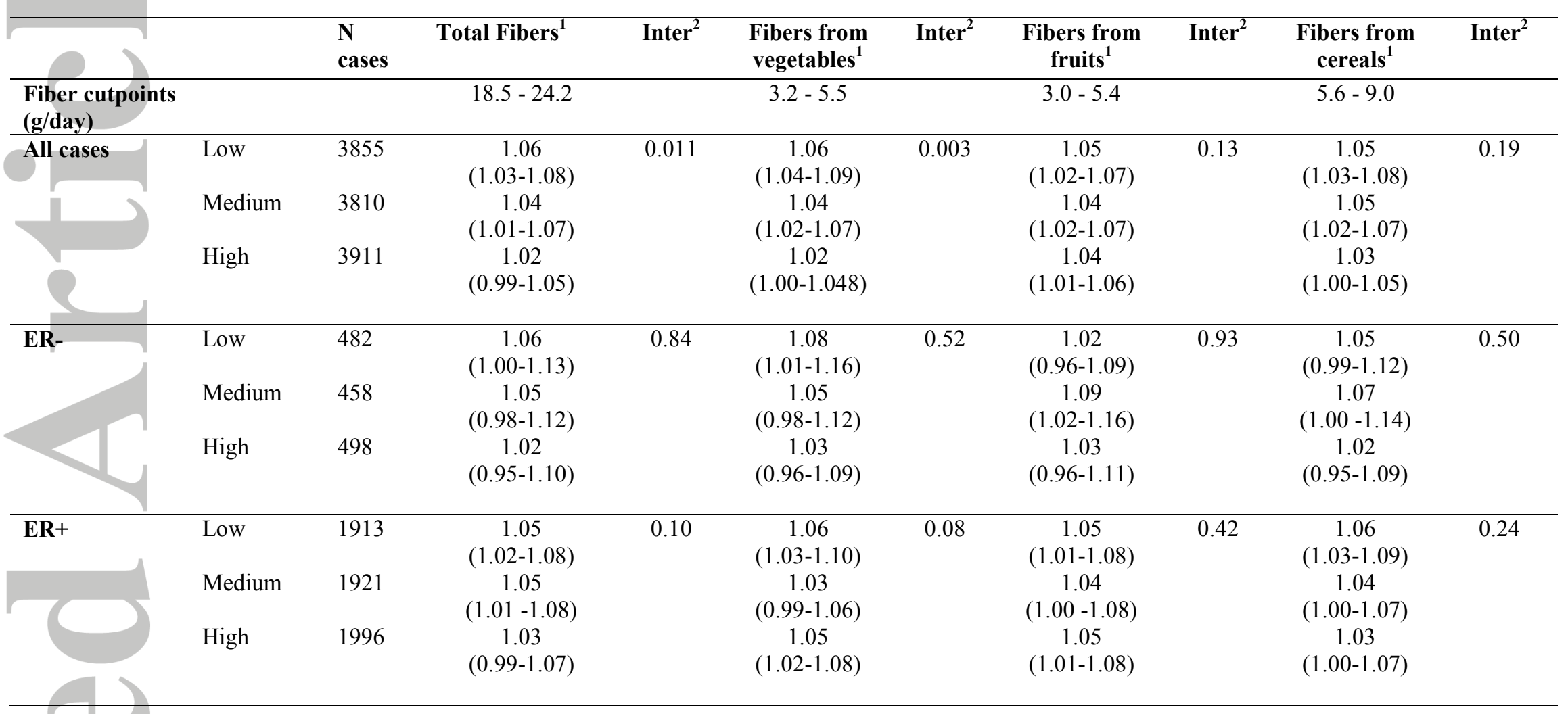

${ }^{1}$ Multivariate model stratified by center and age at recruitment (1-year interval), and adjusted for menopausal status (pre/peri vs postmenopausal women), oral contraceptive use (yes/no), hormone replacement therapy use (yes/no), height (continuous), weight (continuous), interaction menopause and weight, smoking status (never, ex, current), educational level (primary/no schooling, technical/professional/secondary, longer education,), physical activity (inactive, moderately active, moderately inactive, active ), age at first menses $(\leq 12,13-14,15+$, ), age at first full term pregnancy (nulliparous, $\leq 21,22-30,>30$, $)$ age at menopause $(<50, \geq 50$,$) and energy intake without alcohol intake.$

${ }^{2} \mathrm{p}$ for interactions was assessed using likelihood ratio tests based on the models with and without the interaction terms of dietary fiber and alcohol intake at recruitment (both in continuous). 


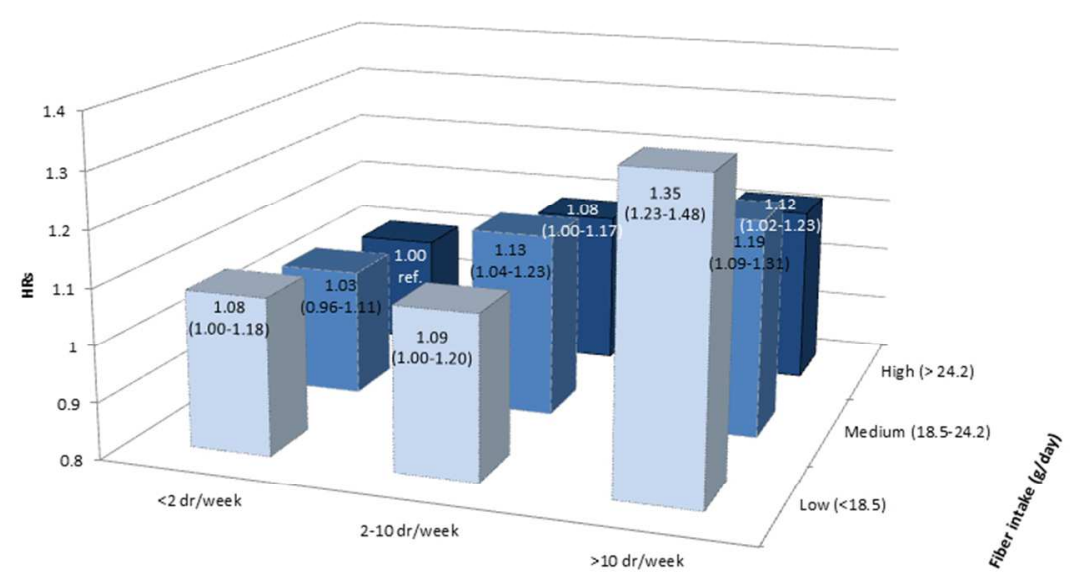

Alcohol intake

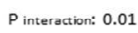

Figure 1: Multivariate hazard ratios (HR) with $95 \%$ confidence intervals $(\mathrm{Cl})$ for breast cancer according to the combined effects of dietary fibers (g/day) and alcohol (drink/week)

Footnote: Non consumers of alcohol were excluded

Figure 1: Multivariate hazard ratios (HR) with $95 \%$ confidence intervals (CI) for breast cancer according to the combined effects of dietary fiber ( $\mathrm{g} / \mathrm{day}$ ) and alcohol (drink/week)

$254 \times 190 \mathrm{~mm}(96 \times 96 \mathrm{DPI})$
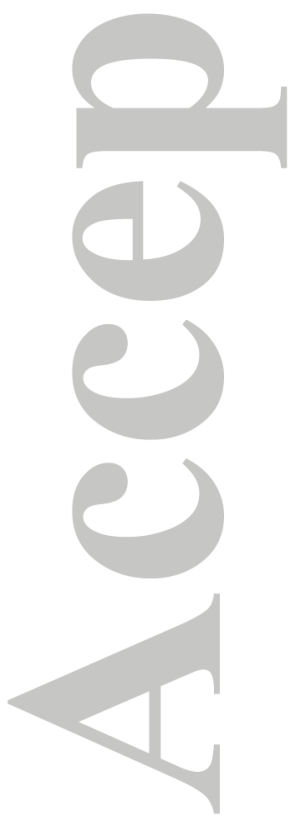

John Wiley \& Sons, Inc.

This article is protected by copyright. All rights reserved. 